\title{
The Policy and the Strategy of the Provision of Bicycle Lane in East Java, Indonesia
}

\author{
Muhammad Zainul Arifin*, Harnen Sulistio \\ Brawijaya University, Faculty of Engineering, Department of Civil Engineering, \\ Malang, Indonesia
}

*Corresponding Author: Muhammad Zainul Arifin: mzaftub@gmail.com; mzaub@yahoo.co.id

\section{OPEN ACCESS}

Citation: Arifin M. Z., Sulistio H. (2017) The Policy and the Strategy of the Provision of Bicycle Lane in East Java, Indonesia. Open Science Journal 2(2).

Received: $2^{\text {nd }}$ September 2016

Accepted: $21^{\text {st }}$ April 2017

Published: $27^{\text {th }}$ May 2017

Copyright:@ 2016 This is an open access article under the terms of the Creative Commons Attribution License, which permits unrestricted use, distribution, and reproduction in any medium, provided the original author and source are credited.

Funding: The author(s) received no specific funding for this work.

Competing Interests: The author have declared that no competing interests exists.

\section{Abstract}

Understanding the characteristics of the cyclists and stakeholders' preferences towards the provision of bicycle lanes is the first step for sustainable transportation. The Government support for providing bicycle lanes can increase the number of cyclists, thusreducing the noise and air pollution, and providing safety, discipline and smooth traffic. Therefore, is requred a study of a policy strategy about the provision of bicycle lanes. The aim of this study is to obtain a policy for handling the provision of bicycle lanes based on internal and external factors by considering the preferences of cyclists, road users and stakeholders. Data was collected by interviewing all stakeholders, i.e. the staffs from the City Government of the city of Malang, Jember, and Surabaya and the Department of Public Work Bina Marga of East Java. The analytical method used is SWOT Internal Factor Evaluation-External Factor Evaluation (SWOT IFEEFE).Analysis of matrix of external and internal factors for the provision of bicycle lanes explains that positions of the current condition and the future condition are in the cell V $(2.451 ; 2.493)$ and in the cell I $(3.338 ; 3.135)$ respectively. The position of the cell V and the cell I indicates that the provision of bicycle lanes under development is a position of grow and develop.The development strategy can be applied through vertical integration thus all the strategic elements of government and stakeholders are able to jointly reformulate the strategy, starting from the preparation of legal protection for the provision of bicycle lanes in the neighborhood ("RT/RW") of sub-district. The city authority is expected to reinforce the operational implementation. Meanwhile, the preference weight towards the provision of bicycle lanes of road users and stakeholders is $83.7 \%$. Herewith the provision of dedicated bicycle lanes is required. 
Keywords: Bicycle lane, policy strategy, preferences of stakeholders, cyclist, SWOT (IFE-EFE)

\section{Introduction}

Law number 22 of 2009 of Republic of Indonesia regulates the non-motorized vehicles. The Government should provide a dedicated cyclists lane. Cyclists are entitled to use this lane for security, safety, discipline, and fluency in transportation. Local governments can determine the type of used non-motorized vehicles in accordance with the characteristics and the needs of the regions.

Cyclists generally are people with low income because they could not have a car or other motor vehicles. According to [1], the provision of bicycle lanes for cyclists is based on socio-economic characteristics (SECh), bicycle ownership (BO) and movement characteristics (MCh). The weight of the perception towards the provision of bicycle lanes (PPBL) for cyclists was $63.4 \%$. [1] also stated that the best policy for cyclists is designed according to the socio-economic characteristics, i.e. the criteria of safety aspects (48.78\%), comfort aspects $(14.1 \%)$, and travel time aspects $(6.4 \%)$.

Cycling behavior in Edmonton in Canada is influenced by the time spent cycling, the secure parking, and the level of cyclist' experience. The time spent cycling in mixed traffic is more difficult than time spent cycling on bike lanes [2]. The provision of extensive cycling rights in the Netherlands, Germany and Denmark is encouraged by providing a bike parking, full integration with public transport, comprehensive traffic education and training of both cyclists and motorists, as well as a wide range of promotional events intended to generate enthusiasm and wide public support for cycling. The policy to increase the use of bicycle is also supported by a host of taxes and restrictions on car ownership, car use and parking [3]. Previous literatures, do not provide in-depth assessment of policy strategies and opportunities for the provision of bicycle lanes in developing countries, particularly Indonesia, based on preferences of the cyclists, non-cyclists, and policy makers to the infrastructure facility conditions. This study intends to address the importance of stakeholders' preferences in providing bicycle lanes based on internal and external factors.

The paper is structured as follows: Materials and methods are presented in Section 2. Section 3 explains results and discussions about assessment of matric internal external, internal and external factors influencing a bicycle lane. Conclusions and recommendations are presented in Section 4.

\section{Materials and Methods}

The method used for data collection was direct interview surveys by distributing questionnaires to all stakeholders consisting of staffs of City Government of Malang, Jember, Surabaya and the Department of Public Work Bina Marga of East Java. The analytical method was SWOT Evaluation Factor 
Internal-External Factor Evaluation (IFE SWOT-EFE) supplied commercially. Completely resources were used deprived out of any purification.

\section{Internal External Matrix(IE)}

This analysis tool is used to measure the magnitude of Opportunity or Threat with provision of bicycle lanes and to assess the extent of factors of Strengths or Weaknesses for the provision of bicycle lanes.

Here are the steps in preparing Internal External Matrix [4].

\section{1) Internal Factor Evaluation /IFE}

IFE method was used to determine the internal factors affecting the provision of bicycle lanes related to Strengths and Weaknesses, which were considered important. Data were extracted from some potential sources for the provision of bicycle lanes, such as aspects of human resource, operation, finance and marketing.

\section{2) External Factor Evaluation / EFE}

EFE method was used to evaluate the external factors. The data were related to factors concerning economy, social, culture and demography, law and government, as well as technology. These factors are important because external factors are influencing directly or indirectly in providing bicycle lanes.

3) Internal - External (IE) Matrix

The Parameters in IE matrix were internal strength and external factors influencing a realization of bicycle lanes. IE matrix is useful to a position in a matrix comprising 9 cells. IE matrix composes of two dimensions, i.e. the total score of the IFE on the $\mathrm{X}$ axis and the total score of EFE matrix on the $\mathrm{Y}$ axis.

\section{Factors and Indicators of each factor were structured as follows:}

Internal Factors include:

1) Human Resource

a. The majority of cyclists are in their productive age (15-35 years);

b. An awareness of preserving the environment depends on increase of educational background of cyclists.

2) Operational

a. Mixed traffic conditions are in the present time and separated traffic conditions are in the future;

b. Cyclists understanding of cycling safety.

3) Finance

a. Vehicle Operating Cost (VOC) of bicycle is low;

b. Increased revenue of cyclists increases a willingness to buy a motorcycle as transport mode.

4) Marketing 
a. The action program for the socialization of cycling movement relates to changing non-cyclist behavior to a bicycle as transport mode;

b. The special day of cycling for employees of government agencies, private sectors, and school/ university students should be established;

c. Imposition of road tax for the users of motorized vehicles is expected to increase the use of bicycles.

External Factors include:

1) Economy

a. Macroeconomic conditions have an effect in ability to purchase a motor vehicle.

2) Law and Government

a. Implementation of Law No. 22 of 2009 on LLAJ (chapter 25 and 45) for provision of bicycle lanes;

b. Regional Regulation of East Java No. 9 Year 2010 concerning Regional Tax (Article 8); progressive tax motorcycles (> 250cc);

c. Credit policy for purchasing cars / motorcycles with low down payment;

d. The government prioritize a policy for the provision bicycle lanes and its implementation in the "RT/RW" and city/ sub-district;

e. The government prioritize the establishment of bicycle lanes permanently with concrete markers;

3) Social culture and demographics;

a. The non-cyclists will feel comfortable, orderly, safe, secure and swift with dedicated-bicycle lanes;

b. The non-cyclists will use the transportation mode of bicycles with dedicatedbicycle lanes;

c. The non-cyclists despise the cyclists;

4) Technology;

a. The increase of road capacity by widening lane;

b. Provision of dedicated-bicycle lanes.

\section{Results and Discussion}

\section{Results}

\section{A. Internal Audit}

Analysis of the internal environmental factors (IFE), demonstrate that each factor in the present time indicates low value rating (below 2.5) or as "Weakness" variable, excluding the human resources factor, as explained in Table 1. Meanwhile, all internal environmental factors have high values (above 2.5) indicating "Strength" variable.

\section{B. External Audit}

Analysis of environmental factors External (EFE), demonstrate that at the present time the factors related with economy, law and administration (a and c), culture and demography (c) and technology (a and b) have low values (below 
2.5), categorized as "Threat" variable. While in the near future, all rating values are high (above 2.5), categorized as "Opportunity" variable, excluding one factor indicator on Law and Government, i.e. c indicator, as seen in Table 2.

Table 1 Summary of the rating on IFE factors

\begin{tabular}{cllllll}
\hline \multirow{2}{*}{ No } & \multicolumn{2}{c}{ Statement } & \multicolumn{2}{c}{ Present } & \multicolumn{2}{c}{ Future } \\
\hline \multirow{2}{*}{ Human } & a. & 3,012 & Strengths & 3,221 & Strengths \\
& resource & b. & 3,209 & Strengths & 3,523 & Strengths \\
\hline \multirow{2}{*}{2} & \multirow{2}{*}{ Operational } & a. & 1,849 & Weakness & 3,477 & Strengths \\
& & b. & 2,570 & Strengths & 3,570 & Strengths \\
\hline \multirow{2}{*}{3} & \multirow{2}{*}{ Finance } & a. & 2,593 & Strengths & 3,221 & Strengths \\
& & b. & 2,465 & Weakness & 2,884 & Strengths \\
\hline \multirow{2}{*}{4} & \multirow{2}{*}{ Marketing } & a. & 1,779 & Weakness & 3,500 & Strengths \\
& & b. & 1,721 & Weakness & 3,244 & Strengths \\
& & c. & 1,709 & Weakness & 3,291 & Strengths \\
\hline
\end{tabular}

Table 2 Summary of the rating EFE factors

\begin{tabular}{cllllll}
\hline No & \multicolumn{2}{c}{ Statement } & \multicolumn{2}{c}{ Present } & \multicolumn{2}{c}{ Future } \\
\hline I & Economy & a. & 2,198 & Threat & 2,570 & Opportunity \\
\hline II & Law and & a. & 1,744 & Threat & 3,419 & Opportunity \\
& Government & b. & 2,919 & Opportunity & 3,302 & Opportunity \\
& & c. & 2,012 & Threat & 2,140 & Threat \\
& & d. & 2,919 & Opportunity & 3,442 & Opportunity \\
& & e. & 2,767 & Opportunity & 2,919 & Opportunity \\
\hline \multirow{2}{*}{ III } & Social & a. & 3,035 & Opportunity & 3,651 & Opportunity \\
& culture and & b. & 2,826 & Opportunity & 2,802 & Opportunity \\
& demographic & c. & 1,779 & Threat & 2,558 & Opportunity \\
& s & & & & & \\
\hline \multirow{2}{*}{ IV } & Technology & a. & 2,372 & Threat & 3,395 & Opportunity \\
& & b. & 1,686 & Threat & 3,500 & Opportunity \\
\hline
\end{tabular}

\section{Discussion of SWOT (IFE-EFE) Results}

The current positions of internal and external variables of the provision of bicycle lanes are Weakness and Threat, indicated with total score less than 2.5. Those positions turn into Strengths and Opportunity in the near future, because of total score more than 2.5, as explained in Table 3. 
Table 3 Value Score of IFE-EFE

\begin{tabular}{|c|c|c|c|c|c|c|}
\hline \multirow{2}{*}{$\frac{\text { No }}{1}$} & \multirow{2}{*}{$\begin{array}{c}\text { Institution } \\
\text { Government }\end{array}$} & \multirow{2}{*}{$\frac{\text { IFE-EFE }}{\text { Internal }(\mathrm{X})}$} & \multicolumn{2}{|c|}{ Present } & \multicolumn{2}{|c|}{ Future } \\
\hline & & & 2.429 & Weakness & 3.395 & Strengths \\
\hline & Staff of & & & & & \\
\hline & Malang City & & & & & \\
\hline & The Regional & External (Y) & 2.395 & Weakness & 3.052 & Strengths \\
\hline & Planning and & Internal (X) & 2.521 & Strengths & 3.250 & Strengths \\
\hline & Development & & & & & \\
\hline & Department of & External (Y) & 2.675 & Strengths & 3.225 & Strengths \\
\hline & Transportation & Internal (X) & 2.352 & Weakness & 3.363 & Strengths \\
\hline & Public Work & External (Y) & 2.773 & Strengths & 3.417 & Strengths \\
\hline & Department & Internal (X) & 2.375 & Weakness & 3.091 & Strengths \\
\hline & Police Resort & External (Y) & 2.646 & Strengths & 2.843 & Strengths \\
\hline \multirow[t]{2}{*}{2} & Academicians & Internal (X) & 2.270 & Weakness & 3.535 & Strengths \\
\hline & FTUB & External (Y) & 1.891 & Weakness & 3.355 & Strengths \\
\hline \multirow[t]{8}{*}{3} & Government & Internal (X) & & Strengths & & \\
\hline & Staff of & & 2.593 & & 3.371 & Strengths \\
\hline & Surabaya City & & & & & \\
\hline & The Regional & External (Y) & 2.763 & Strengths & 3.417 & Strengths \\
\hline & Planning and & Internal (X) & 2325 & Weakness & 2991 & Strenoths \\
\hline & Development & & 2.325 & & 2.991 & Strengtns \\
\hline & Department of & External (Y) & 2.617 & Strengths & 3.200 & Strengths \\
\hline & Transportation & & & & & \\
\hline \multirow[t]{11}{*}{4} & Department of & & & & & \\
\hline & Public Work & & & & & \\
\hline & of East Java & & & & & \\
\hline & Province & & & & & \\
\hline & Staff of Public & Internal (X) & 2.531 & Strengths & 3.247 & Strengths \\
\hline & Work & & & & & \\
\hline & & External (Y) & 2.616 & Strengths & 3.256 & Strengths \\
\hline & Staff of Bina & Internal (X) & 2.666 & Strengths & 3.512 & Strengths \\
\hline & Marga & & & & & \\
\hline & (Highway & External (Y) & 2.558 & Strengths & 3.058 & Strengths \\
\hline & Department) & & & & & \\
\hline \multirow[t]{2}{*}{5} & Combined & Internal (X) & 2.451 & Weakness & 3.338 & Strengths \\
\hline & & External (Y) & 2.493 & Weakness & 3.135 & Strengths \\
\hline
\end{tabular}

\section{Positions of the Provision of Bicycle Lanes for the Present and the Future}

In the present time, the internal and external environment have total scores of weighted values of 2.451 and 2,493 respectively. Those values for the future are changing, as can be seen in Table 4 the total scores of a weighted value on the internal and external environment are 3.338 and 3.135 . Thus, , as illustrated in Figure 1 the positions of $(2,451 ; 2,493)$ at the present time are included in the cell $\mathrm{V}$, while for the future time the position of $(3.338 ; 3.135)$ belongs to cell I. 
Positions in cells I and V mean that provision of bicycle lanes under development are in a position of grow and development. As consequence, the development strategy should be applied through vertical integration.

Table 4 Total Score IFE-EFE

\begin{tabular}{ccc}
\hline Total Skor & A(Present) & B(Future) \\
\hline Internal & 2,451 & 3,338 \\
External & 2,493 & 3,135 \\
\hline
\end{tabular}

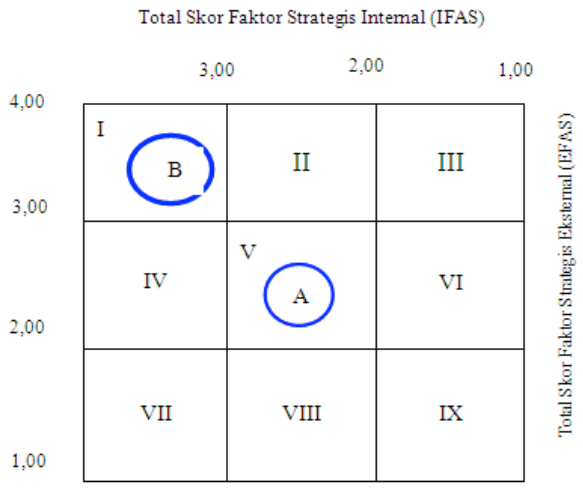

Figure 1 Score Positions of Internal and External Factors (IFE-EFE)

Based on the analysis of SWOT (IFE-EFE), the Government should improve and implement a policy related to the provision of bicycle lanes since at the moment the policy is weak.. The following recommendations are important to be implemented as a part of the policy for the provision of bicycle lanes::

a) HR (Human Resource)

Cyclists are expected to come from all age groups, from school age to old age with the awareness of preserving the environment through cycling.

\section{b) Operational}

On the operational side in the present time, the indicator of Strength is the understanding cycling safety by cyclists. The strengths should be maintained by increasing dissemination of information about cycling safety in every opportunity, particularly in schools. On the other hand, the indicator of Weakness is the existing traffic condition, composed of mixed traffic flow, characterized by a mix use of motorized vehicles and non-motorized vehicles in the same lane. Gradually, the Government should start to prepare separate area for cyclists. Consequently, non-motorized vehicles are separated from motorized vehicles in a specific lane.

c) Finance

From financial aspect, currently the indicator of weakness fis demonstrated through general opinion that "increased income of cyclists will increase ability to buy motorcycles". This is a legitimate because the ability is the individual's rights. However,in the long run, it will cause negative influence on the natural environment, particularly will increase the air pollution. To anticipate this 
condition, the Government should accommodate viable, safe and comfortable public transportation in order to reply to the citizens' needs for transport. The citizens can be served by an adequate public transportation. Meanwhile, understanding the low operating vehicle cost of bicycle is Strengths indicator, which should be maintained by promoting cycling which is not costly to be operated and can nourish the body.

\section{d) Marketing}

The marketing of provision of bicycle lanes for present time is still an element of Weakness. For that reason, the Government should intensively and periodically undertake a socialization as follows:

a. The action program for the socialization of cycling movement, related to changing behavior on a bicycle mode;

b. Establishment of the special cycling day for employees of government institutions, private sectors, and school/ university students;

c. Imposition of road tax for motorized vehicle users by local government intended to increase the willingness of using bicycle.

For the external environment, the Government should be able to execute the strategy with improving the implementation policy, which is a threat for the present time. The policy for the provision of lane bicycles can be developed in the future as follows:

\section{Economy}

The present global economic condition was worrying threat. With macro economy growing well, it will increase an ability to purchase, particularly motor vehicles. To control citizens' willingness to buy motor vehicles, government should set up a policy, which primarily concerns to the provision of adequate public transportation facilities, which can be used for daily movement for citizens aimed to reduce purchase of a motor vehicle.

\section{Law and Governance}

The Provision of Bicycle Lanes has been issued under the Law No. 22 of 2009. On the other hand, insufficient implementation is undertaken on the field. In the future, the Government should describe the policy to be conveyed in legislation related to the province, sub-district, and neighborhood ("RT/RW"). Starting from "RT/ RW", the provision of permanent concrete marker bicycle lanes on the road where the width is more than or equal to seven meters should be prioritized.

There is a policy of progressive taxation, issued under the Regional Law No. 9 Year 2010 ("Perda Jatim") concerning Regional Tax (Article 8). The regulation is about motorcycle progressive tax, applied to motorcycles with a cylinder capacity $>250 \mathrm{cc}$. This regulation is considered as opportunity for the present time and for the future since implementation of this regulation will control a surge on demand/sales of motor vehicles, especially the two-wheeled ones. Hence, the 'screening' policy is expected to be able to control the growth of number of vehicles on the road.

The law is definitely not directly related to the provision of Bicycle Lane. The progressive taxes are expected to be able to control a surge in demand 
(Financial variable indicator No. 3 point b in IFE). A purchase of motorcycle will increase with the increase of cyclists' income, as Strengths indicator. On the other hand, a policy product on credit of purchase of cars/ motorcycles with low down payment, as Threat indicator for the present time and the future. Hence, the policy product should be managed intended to minimize problems related to the purchase of a motor vehicle.

\section{III.Social Culture and Demography}

According to non-cyclists' preferences, the provision of bicycle lanes for the present and future was an Opportunity that should be maintained. Cyclists feel comfortable and safe when cycling on bicycle lanes. Nevertheless, non-cyclists underestimate cyclists because of low financial ability of cyclist. However, this will be an optimistic consideration for the future with an intensive socialization at every opportunity. As consequence, there are an equality for all road users and a good awareness to preserve the environment for cycling.

\section{IV.Technology}

The provision of bicycle lanes for present time is very difficult, considered as Threat, because of limitation of highway capacity. For the Future with improving road capacity by widening of the roads, the effort of provision of bicycle lane is expected as Opportunity indicator. The improvement should be supported by implementation of law enforcement on road signs of sidewalk and road shoulder intended to realize the provision of dedicated-bicycle lanes.

\section{Potential of Perception towards Provision of Bicycle Lanes}

Cyclists' preferences towards the provision of bicycle lanes in East Java is explained as follows [1]:

$\mathrm{PPBL}(\mathrm{C})=0,731 \mathrm{SECh}+0,099 \mathrm{BO}+0,039 \mathrm{MCh} \quad\left(\mathrm{R}^{2}=0,634\right)$

which

SECh = Socio-Economic Characteristics,

$\mathrm{BO}=$ Bicycles Ownership,

$\mathrm{MCh}=$ Movement Characteristics,

$\operatorname{PPBL}_{(\mathrm{C})}=$ Perception of Cyclist towards the Provision of Bicycle Lanes.

Model of non-cyclists' preferences towards the provision of bicycle lanes in East Java [1]:

$\mathrm{PPBL}(\mathrm{NC})=0.385 \mathrm{SECH}+0.064 \mathrm{KKB}+0.411 \mathrm{BO}+0.891 \mathrm{MCh}\left(\mathrm{R}^{2}=0.854\right)$

which

$\mathrm{SECh}=$ Socio-Economic Characteristics,

$\mathrm{KKB}=$ Motor Vehicle Ownership,

$\mathrm{BO}=$ Bicycle Ownership,

$\mathrm{MCh}=$ Movement Characteristics, 
$\operatorname{PPBL}_{(N C)}=$ Non-Cyclist preferences towards the Provision of Bicycle Lanes (Non-Cyclists)

An assessment of stakeholders' preferences to the provision of bicycle lanes was ranked [5] as follows:

Alternative I (Need to establish bicycle lanes with permanent lane separators) $=56.9 \%$,

Alternative II (Need to establish non-permanent bicycle lanes) $=32.0 \%$, Alternative III (No need to establish dedicated-bicycle lane) $=11.1 \%$.

Analysis of preferences towards the Provision of Bicycle lanes (PPLS) is summarized in Table 5. Table 5 shows that the average value of preferences from three groups, i.e. cyclist, non-cyclist and stakeholders is $83.7 \%$.

Table 5 Preferences towards Provision of Bicycle Lanes

\begin{tabular}{|c|c|c|}
\hline No. & Preferences & Potency $(\%)$ \\
\hline \multirow[t]{2}{*}{1} & Cyclist & 73.1 \\
\hline & $\mathrm{SECh} \rightarrow \mathrm{PPBL}$ & \\
\hline \multirow[t]{2}{*}{2} & Non-Cyclist & 89.1 \\
\hline & $\mathrm{MCh} \rightarrow \mathrm{PPBL}$ & \\
\hline \multirow[t]{4}{*}{3} & Stakeholders & 88.9 \\
\hline & $\mathrm{I}=56.9 \%$ & \\
\hline & $\mathrm{II}=32.0 \%$ & \\
\hline & Average & 83.7 \\
\hline \multicolumn{3}{|l|}{ Note: } \\
\hline SECh: & \multicolumn{2}{|c|}{ Socio-Economic Characteristics } \\
\hline MC: & \multicolumn{2}{|c|}{ Movement Characteristics } \\
\hline PPBL: & \multicolumn{2}{|c|}{ Perception towards the Provision of Bicycle Lanes } \\
\hline I: & \multicolumn{2}{|c|}{ Alternative I with the exclusive lanes } \\
\hline II: & \multicolumn{2}{|c|}{ Alternative II with line markers } \\
\hline
\end{tabular}

\section{Conclusion}

The development strategy of the Provision of Bicycle Lanes is in the phase of development. The strategy can be applied by developing a vertical integration consisted of all strategic elements of government and stakeholders who are able to jointly re-formulate a regulation to promote the provision of bicycle lanes in the neighborhood ("RT/RW"), Sub-districts, City and Province. The government is expected to reinforce the strategy by generating an operational budget intended to develop the provision of bicycle lanes for the present time as well as for the future.

Preparation of a framework for the provision of bicycle lanes with new programs includes improvement of road performance, such as controlling the function of sidewalk and road shoulder, establishing a specific area for bicycle lanes, bicycle parking lot and introducing sustainable transportation in 
curriculum starting from elementary education level in order to increase the level of understanding of the importance of cycling by the young generations.

The Government and stakeholders should continuously and consistently establish an action program for socialization of cycling movement related to behaviors of cyclists and non-cyclists. The action programs include an establishment of special cycling day for employees of government agencies, private sectors and school/ university students, an enactment of car free areas. Additionally, it should be introduced a road tax or road pricing for users of motor vehicles in order to increase the use of the bicycles.

An average value of preferences from three groups, i.e. cyclists, non-cyclists and stakeholders towards the provision of bicycle lanes is $83.7 \%$. It means that the provision of bicycle lane is a primary requirement for increasing the use of bicycle.

\section{References}

Arifin, M. Z., Sulistio, H., Wicaksono, A., Djakfar, L., 2013a. Availability model of bicycle path due to the perception of cyclist or non-cyclist in East java Province of Indonesia. Journal of Basic and Applied Scientific Research (JBASR) 3, 545-551.

Arifin, M. Z., Sulistio, H., Wicaksono, A., Djakfar, L., 2013b. Policy on the bicycle lanes provision in East java. Australian Journal of basic and Applied Sciences (AJBAS) 7(11), 247-251.

David, Fred R., 2011, Strategic Management, Book I, 12th edition, Salemba Empat, Jakarta, Indonesia

Hunt, J. D., Abraham, J. E., 2007. Influences on bicycle use, Transportation 34, 453-470.

Pucher, J., Buehler, R., 2008. Making Cycling irresistible: Lessons from The Netherlands, Denmark and Germany. Transport Review 28 (4), 495-528, July 2008. 